\title{
What Stands in the Way of Bigger Internet with Virtually Unlimited IP Address in Cameroon: A Study of IPv6 Stakeholders in Cameroon
}

\author{
Austin Oguejiofor Amaechi, Kongnso Emmanuel Shinyuy \\ Department of Information and Communication Technology, The ICT University, Cameroon Campus, Yaoundé, Cameroon \\ Email: austin.amaechi@ictuniversity.edu.cm
}

How to cite this paper: Amaechi, A.O. and Shinyuy, K.E. (2021) What Stands in the Way of Bigger Internet with Virtually Unlimited IP Address in Cameroon: A Study of IPv6 Stakeholders in Cameroon. Journal of Computer and Communications, 9, 22-36. https://doi.org/10.4236/jcc.2021.911002

Received: September 12, 2021

Accepted: November 5, 2021

Published: November 8, 2021

Copyright $\odot 2021$ by author(s) and Scientific Research Publishing Inc. This work is licensed under the Creative Commons Attribution International License (CC BY 4.0).

http://creativecommons.org/licenses/by/4.0/ (c) (i) Open Access

\begin{abstract}
The purpose of this case study paper was to identify factors that Internet Protocol stakeholders consider as standing in the way of the transition to bigger, more secure and faster internet with virtually unlimited Internet Protocol address in Cameroon and was completed in two phases. Descriptive method was followed and two study instruments were designed and implemented, namely focus group interviews and questionnaire interviews. Both instruments were validated and implemented on a sample of (6) experts for the interviews and (115) for the questionnaire. The focus group data were analyzed using a thematic analysis technique, leading to the identification of six themes including lack of policies and incentives to promote IPv6 deployment at government level, many organizations are seeing IPv6 as an issue that will only affect them in the distant future and not looking at IPv6 technology as an innovation generation opportunity. Decisions on these issues need to change if IPv6 current status in Cameroon is to change. The findings were then validated in the final phase. This involved the deployment of a survey questionnaire to collect opinions of 115 IPv6 actors working in both public and private institutions in Cameroon. The results revealed that IPv6 was not sufficiently attended to by organizations in Cameroon. The study results may be of practical use for Government IT decision makers. A further and more comprehensive research into the topic is recommended.
\end{abstract}

\section{Keywords}

IPv4, IPv6, Internet, Barriers, Facilitators, Technology Management, Cameroon, Thematic Analysis

\section{Introduction}

Understanding the reasons for resistance is very important as a means of identi- 
fying factors which inhibit or encourage the adoption of new technology [1], and provide a better strategy [2] to facilitate the implementation. The reason for resistance to change is not a simple, single causal factor [3] and could vary from one technology to another [4]. Internet Protocol (IP) addresses are the globally unique numeric identifiers necessary to distinguish individual entities that communicate over the Internet. IPv6 is the next-generation Internet protocol, designed to replace version 4 (IPv4) that has been in use since 1983. The sustainable development and evolution of IP infrastructure is essential to the cyberspace and digital economy. In Cameroon, even with the Anglophone crisis and the COVID-19 pandemic, the Internet penetration is rapidly changing. Although, an increasing number of systems are being connected to the Internet to improve availability, performance, and connectivity every day, the adoption of IPv6 is not taking big steps forward at the moment. It is widely recognized that full transition to IPv6 is the only viable option to ensure future growth and innovation in Internet technology and services. Pv6 is widely recognized as an innovation opportunity. Having IPv6 architecture means faster and bigger internet because of improved routing techniques. IPv6 can provide a virtually unlimited number of unique addresses. With IPv6, it becomes possible to know where every piece of data is from, which machine it was sent from, and who received it. IPv6 is a type of digital infrastructure and organizations rely on their digital infrastructure to operate effectively. The degree to which users accept or adopt digital infrastructure remains a key interest of information systems research [5]. Cameroon and indeed Africa have to wake up from their lackluster attitude to investment in this kind of digital infrastructure.

Indeed, IPv6 has gained significant traction in recent years: In August 2016, Google reported that almost 13\% of their users accessed their services via IPv6. This number increased by an order of magnitude in just three years from 1.3\% as of July 2013. In September 2020, according to the Google's statistics, the deployment stood at $30 \%$, which is a great improvement compared to 2016 . The statistics show that the users accessing services via IPv6 is continually increasing. Today [August 7, 2021], it is over 35\% [see

https://www.google.com/intl/en/ipv6/statistics.html]. Google in capturing and publishing this information hope to help Internet providers, website owners, and policy makers in their decisions as the industry rolls out IPv6. Many other network operators have deployed IPv6 to significant parts of their network. The global picture shows that the deployment of IPv6 worldwide is not uniform. Countries where either market conditions or local regulators have stimulated the adoption of IPv6 show clear sign of growth. Countries such as Belgium, France and Germany are well ahead in terms of IPv6 adoption. Globally, the most active areas of IPv6 growth are in South Asia and Oceania. IPv6 is distributed in Africa by the Regional Internet Registry-AFRINIC. The top 5 countries with most IPv6 resources according to https://afrinic.net/quick-facts-ipv6 publication are: South Africa, Nigeria, Kenya, Tanzania and Ghana. Some Governments have tried to force a move to IPv6. Although, many governments are pressing for mandates 
but it is not a regulatory issue. There are not many signs that Cameroon is joining other countries in pushing for the adoption of this new worldwide Internet Protocol that could make the internet bigger and faster, but also potentially less anonymous. We reviewed the main facilitators and barriers for integrating IPv6 technology illustrated in the academic literature [6] [7] [8]. It appears that most of them can either be a driver, or an obstacle, depending on the direction they impact the firm (positive or negative).

\section{Research Objectives and Questions}

IPv6 is a type of digital infrastructure. The degree to which users accept or adopt digital infrastructure has always been a key interest of information systems research [5]. Despite being proposed over 20 years ago [9], IPv6's internet-wide adoption has been a long and slow process. However, over the last 5 - 10 years, IPv6 deployment levels have increased significantly [10], fueling interest in understanding IPv6 use in practice. The present study was carried out to explore perceptions of participants of single objectives of identifying factors that [IPv6] digital infrastructure actors in the Cameroon considered as standing in the way of bigger Internet with virtually unlimited IP address; that is, reasons why IPv6 adoption rate is low in Cameroon. The main research question that guided this study was:

What are the factors standing in the way of bigger Internet with virtually unlimited IP address in Cameroon or influencing the scope of her wide adoption? Sub questions includes: what extent does the awareness towards IPv6 exist in the Cameroonian organizations? What is the institutional current status to support the deployment of IPv6?

Systems approach and descriptive viewpoint was found the most appropriate to answer the questions of this study. According to [11], systems approach considers the attributes of an entire system to achieve the objective of a system, which is to solve a problem. The research questions informed the direction of this research both theoretically and methodologically.

The structure of this paper is as follows: After this introduction, Section 2 describes the research methodology and Section 3 is concerned with the results from the study undertaken. The paper is then concluded and recommendations are made for future work.

\section{Methological Approach}

Systems approach and descriptive method was found the most appropriate to answer the questions of this study. The core concepts allowed participants to adequately explore and express their perceptions. The purpose of this case study was to identify factors that our Internet Protocol target actors consider as standing on the way of the transition to bigger, more secure and faster internet with virtually unlimited Internet Protocol address in Cameroon. The identified actors are first, the technicians who are performing the configuration process. Next are their managers. Managers play a role because they prioritize on what the engi- 
neers work. Engineers and managers as actors are part of organizations which are connected to the Internet. Another group of actors are ISPs, Internet Service Parties, and hosting parties. We considered them actors because they supply connectivity and infrastructure to connecting organizations and individuals. Then, there are internet governance agencies [and in our study, they are the government agencies and ministries] who are supposed to be responsible for maintaining, spreading knowledge, and improving the Internet and finally, University teachers who preparing the next generation of technicians and managers. A near exploratory sequential design (see Figure 1) was employed in which a quantitative questionnaire investigating stakeholders' satisfaction of the factors influencing transitions to IPv6 technology was set up, informed by the qualitative study on which what stands in the way of bigger Internet with virtually unlimited IP address (factors influencing transitions to IPv6 technology) in Cameroon had been expressed. The study in general took a total period of 32 weeks in order to be successfully completed.

This study was completed in two phases.

\section{Stage I-Focus Group Interviews}

In the first, a focus group with six experts drawn from the defined actors and working with different organizations was conducted to gain a high-level overview of the research domain. The qualitatively collected data were analyzed using a thematic analysis technique, leading to the identification of six themes.

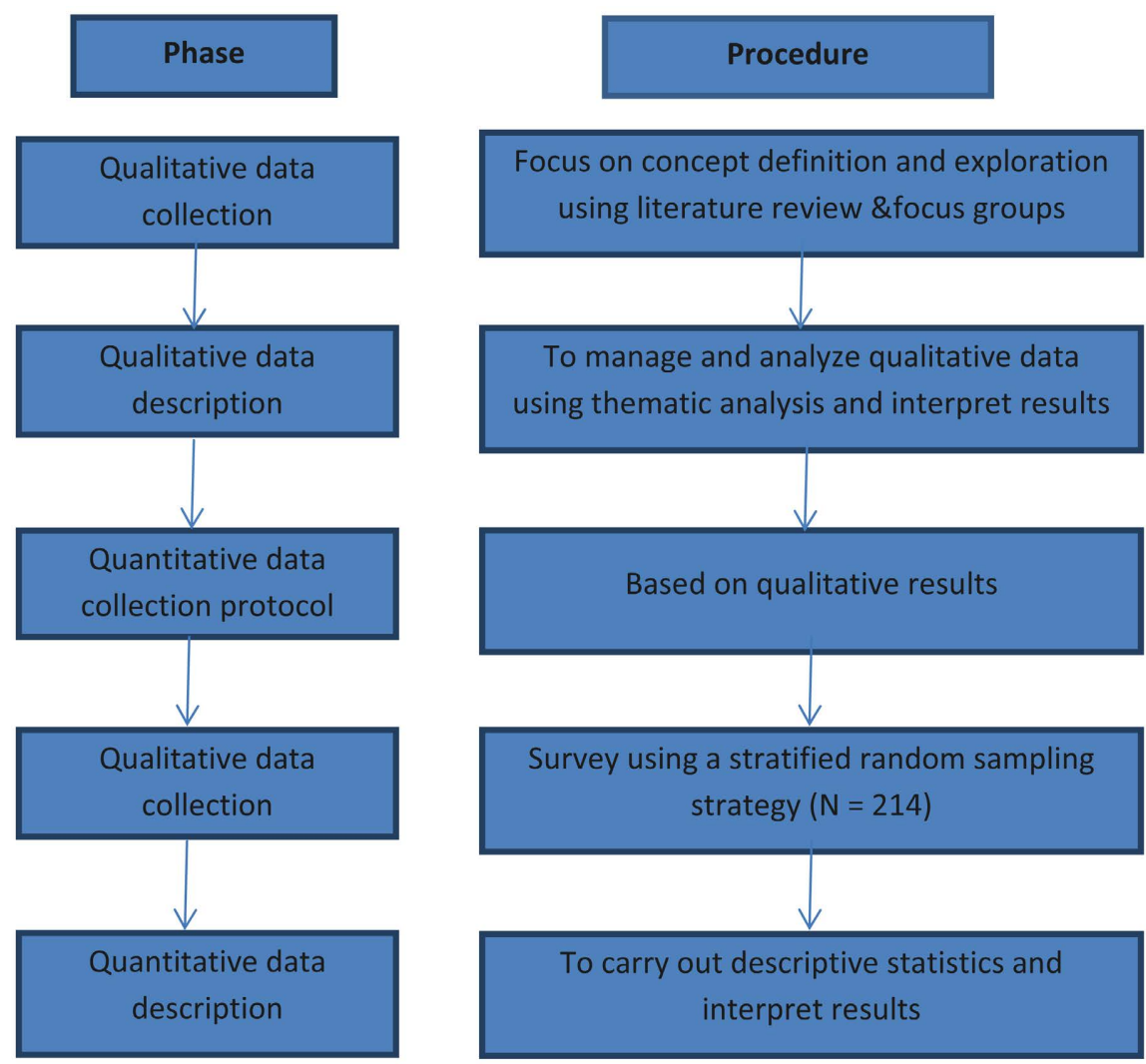

Figure 1. A near exploratory sequential design representation. Source: Authors. 
Each was discussed and agreed in the focus group as important in the status of IPv6 adoption and adaption in Cameroon. Analysis of focus groups data can be conducted in various ways, depending on the goals of the researcher. In this paper, data analysis was guided by both the study objectives (deductive) and readings and interpretations of the raw data (inductive). Thematic analysis (Miles \& Huberman, 1994) as used in this paper is a method of identifying and reporting patterns. Identifying recurring messages and unifying situations is the basis of thematic analysis.

Stage II-Questionnaire Survey

The second stage of the study was based on a questionnaire survey that was aimed at understating the stakeholders' perceptions of the significance of each of the findings discussed in stage 1 . This involved the deployment of a survey to collect opinions of 115 IT staff with work experience in public and private institutions, service providers, and universities in Cameroon. The valid information attained from the participants were then analyzed and interpreted. Frequency and percentage were used for analyzing the demographic data.

The mixed methods research reported in this paper is useful for finding credible answers to research questions on complex social phenomena. Our starting point on the whole research aim is that reality is subjective and that there are multiple perspectives of thought [12]. Through the focus groups we brought together different perspectives of Internet Protocol actors from various sectors of activity directly or indirectly linked to IPv6 technology. Focus groups are both an informal conversational interview and an observational technique [13]. Written consent forms were obtained before commencing the interviews with the key informants. During the write-up and report writing, participants were not identified by their names, positions or roles; only codes were used. Based on the above methodological steps, the subsequent section will focus on the data collection and analysis.

\section{Data Collection}

A good assumption of a focus group study method is that subjective beliefs, though they can be incongruent with reality, are important to assess because people's behavior is based on their beliefs or perceptions of reality [14]. As advocated in [15], our study population was selected as their knowledge and perceptions about the IPv6 technology can be used to make decisions for adopting new technologies. We employed purposeful, snowballing-based sampling as a mechanism for both identifying and recruiting the participants. Thus, the participants were involved because of their representativeness, IP network capability, level of connectivity with internet service providers and/or their role in the definition and implementation of national and local policies for the government IT sector. For the purpose of this research and to support data collection for the qualitative focus group, a protocol was built, which included the predetermined open-ended question. For the second phase of this research, a survey was carried out to evaluate the result of the first phase. With the questionnaire, we collected opinions of 115 individuals with work experience in public and private institu- 
tions, service providers, universities in Cameroon and their extent of acceptance or rejection.

\section{Findings \& Discussions}

\subsection{Thematic Analysis}

We applied a coding process, starting with the development of categories. In general, this process, based on Strauss and Corbin [16], involves progressive coding techniques: open coding, axial coding and selective coding. Based on the data analysis, the challenges and facilitators identified through the interviews were disintegrated into six key themes:

Theme 1: Not looking at IPv6 technology from an open systems perspective

Two of the participants from the two government agencies talked on the importance of building open systems digital Government strategy as a framework to a 21 st century digital platform to improve services for both internal and external customers. To them, IPv6 technology represents an opportunity for both government and organizations to communicate the importance that there is no one right way to accomplish important digital infrastructure development in an organization. The participants generally advocated winning IPv6 implementation solutions that include development of shared knowledge, appropriability digital regimes based on trust, network stability and the alignment of heterogeneous interests

Theme 2: Lack of understanding IPv6 Innovation Generation opportunity

In an opinion expressed by one of the participant, nothing will change until the country start seeing IPv6 as an opportunity for innovation generation. IPv6, the participant said is about making the life easier for users (plug \& play). Another participant said: IPv6 is an opportunity for new advanced applications. IPv6 stakeholders in the country must be motivated to see the opportunities available with IPv6 technology. In discussing IPv6 migration strategies and challenges experienced within their organizations, participants described the need to formally drive their organization's IPv6 internal innovation strategy through external partnerships or through wholly owned and dedicated internal departments focused on the development of IPv6-enabled innovative products. To each of the 6 participants, IPv6 is an extensible protocol, open to what we need now and in the future and therefore cost should no more be the problem.

Theme 3: High IPv6 infrastructure cost involving infrastructure upgrade and deployment operation

The cost of the required IPv6 infrastructure is very high for most organization in the country to handle. IPv6 technology adoption decisions are path-dependent. The biggest issue here is IPv6 technology not being backwards compatible, meaning that enabling IPv6 in a network will require organization to maintain reachability over IPv4 as well, at-least until each and every host on the network is IPv6 capable. Different case studies have accepted that the IPv6 deployment in- 
cur significant initial and ongoing costs that are caused by the necessity of maintaining compatibility with IPv4. The IPv6 infrastructure cost involving infrastructure upgrade and deployment operation is seen by all the participants as significant and a major to the overall delay in IPv6 deployment in Cameroon. Any IPv6 deployment does not eliminate the operator's need for IPv4 addresses, nor does it eliminate the need to share those addresses because of the required backward compatibility. All the six experts involved in our study said that their organizations have no budget for IPv6. If looked at from the findings reported in [17], the Cameroonian organizations are not ready to initiate IPv6 implementation. According to [17], organization that plan to initiate the IPv6 transition need to provide the significant budget needed for planning, design, testing, training, deployment operation, and operating costs.

Theme 4: The need for government and organizations to invest in adequate staff training

Engineering skills and knowledge are foundational to technological innovation and development that drive long-term economic growth and help solve societal challenges. In an organization, the technical staffs are required to assess all existing applications to see how they would work with IPv6 and the lack of training may be a barrier to adoption [18] [19]. Majority of the participants indicated that most of the enterprise engineers and technicians they are in contact with don't know or understand fully how IPv6 works. The technicians want to get trained yet their management does not feel that they need it or want to pay for such training because they do not see a business need for IPv6 adoption. The majority of end-user devices are compatible only with the IPv4. This creates an unfortunate cycle where misinformation about the complexity of the IPv6 protocol and unreasonable fears about security and manageability combine with the perceived lack of urgent business needs to prevent adoption of IPv6.

Theme 5: Lack of and need for policy drivers for promoting and incentivizing the transition to IPv6

Although the general consensus is that market forces should be allowed to drive the transition from IPv4 to IPv6, the study participants agreed that market forces would not sufficiently make it a glory for the country. They agreed emphasized the government should foster development and deployment of IPv6. Based on the demand supply application, there are no significant incentives for ISPs to vigorously pursue IPv6 options instead of IPv4, especially since it costs a considerable amount of time and money to upgrade. Participants were of the opinion that the government doesn't show readiness to facilitate the deployment or provides little intention on deployment. Participants pointed to the external influences of government as a driving force behind IPv6 adoption in USA, China and European countries. Cameroon government can participate in promotion IPv6 adoption through activities such as conformance testing and funding of research to develop solutions to interoperability problems. Government agencies could play a significant role as early adaptors of IPv6. In addition, all the participants agrees that the Cameroon government can help to ensure that all IP stake- 
holders are aware of the benefits and costs of IPv6 and disseminate information to organizations to promote the development of cost-effective transition strategies.

Theme 6: IPv6 stakeholders still see IPv6 technology as something for the distant future

Participants are of the opinion that many organizations private and publicdo not even have plans to implement IPv6 in their networks in the next five years. This phase revealed that although most Cameroonian organizations believe that IPv6 is important, they do not consider it to be urgent. While the IT engineers and other ICT experts working for these organizations may understand the importance of the IPv6 issue, top management don't think of the technology as a priority because it simply is not critical to their operations. Two of the study participants working with the two major ISPs in the country confirmed that they do not offer IPv6 to their end customers but only include IPv6 in some of its lines of business, mainly for Internet businesses. Thus, there is no motivation or business pressure based on the current situation. This study tested the IPv6 technology support availability within our study participant's internet network. We asked a simple question: Is your core network able to support IPV6 technology? To verify whether our study participant's PC is already actively using IPv6, the research team asked each participant to use their web browser to navigate to http://test-ipv6.com. The combination of successes and failures tells a story about how ready the participant PC are for when publishers start offering their web sites on IPv6. The responses we got indicate that 79\% of the participants have a No while 21\% has a Yes [all key components of their network infrastructure reported support for both IPv4 and IPv6 traffic]. For the 79\% study participants reporting "No IPv6 address detected," is an indication that the participant has only IPv4 Internet service at time of the test. It could also mean that either their organization is blocking the use of IPv6 to talk to the outside Internet through network policy; or perhaps what they see with IPv6 on their host is not a global address.

Based on the analysis discuss above, such factors as Not looking at IPV6 technology from an open systems perspective, lack of understanding IPV6 Innovation generation opportunity high IPV6 infrastructure cost involving infrastructure upgrade and deployment operation, the need for government and organizations to invest in adequate staff training, lack of and need for policy drivers for promoting and incentivizing the transition to IPV6 and IPV6 stakeholders still see IPV6 technology as something for the distant future can be used to gauge the readiness of an organization at least in Cameroon to face transition to IPV6.

\subsection{Questionnaire Survey}

We designed the surveys for this study on the basis of literature review and qualitative interview noted above. The selection of the sample was purposeful. The respondents were 115 in total and included ICT specialists with experience of implementing, managing the process or IP network systems academics resident 
in Cameroon for at least five years. The participants of the questionnaire survey were asked to "Rate the importance of each of the identified 6 challenges or facilitators necessary for almost non-existent IPv6 deployment decision to change" with weights varying from 5 (Very important) to 1 (Completely unimportant).

\subsubsection{Demographic Analysis}

The structure of data provided by respondents that filled the questionnaire was quantitatively analyzed according to the following criteria: age, nature of use, level of education attained, practical experience regarding Internet Protocol networking administration, and place of residence in the country (Table 1). Persons in the age bracket of 35 - 39.9 dominated in the study group (38.26\%). People with first degree education constituted nearly half of the respondents. Most respondents, about $36 \%$, were individuals working with job role as Network Engineer \& Analyst.

Respondents who were the government decision-makers or managers of government IT in which the ultimate regulatory decisions has to be made amounted to $6.09 \%$, while the IP network educators/post graduate students constituted $27.83 \%$ of the sample. As suggested by Raigor et al. [20], the minimum number of respondents required to achieve accurate results is 100 , thus the sample size achieved seems sufficient to fulfill its purpose.

\subsubsection{Familiarity with IPv6 Analysis}

To evaluate the participants' awareness of the concept of Internet Protocol and Internet protocol version 6 in particular, they were asked: "How familiar are they with the term IPV6?" All of the respondents showed some understanding of the term IPv6, as illustrated in Figure 2.

According to Dell et al. [21], the decision to adopt IPv6 is influenced by the information available to the decision maker. The results in this study show that more than half of the surveyed population (52\%) were [extremely or very familiar] with the concept of a IPv6 technology, while (27\%) were somewhat familiar with this concept, leaving a small minority (21\%) claiming to be [not so or not at all familiar] with this concept.

\subsubsection{Institutional Current Status to Support IPv6 Deployment Analysis}

To assess each particular participant's organization's IPv6 current status or environment, the respondents were asked to answer this study question: "What is

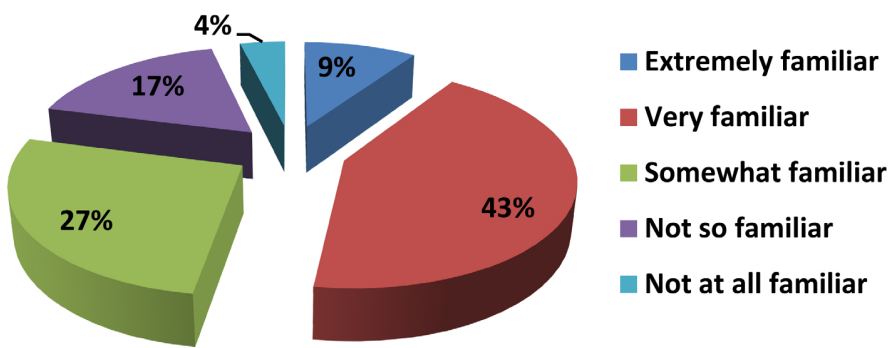

Figure 2. Interview graphical representation. Source: Authors. 
Table 1. Major characteristics of study participants.

\begin{tabular}{|c|c|c|c|}
\hline Sample Characteristics & Values & $\begin{array}{l}\text { No of Valid } \\
\text { Responses }\end{array}$ & Share \\
\hline \multirow{8}{*}{ Age } & $20-24.9$ & 8 & $6.95 \%$ \\
\hline & $25-29.9$ & 16 & $13.91 \%$ \\
\hline & $30-34.9$ & 27 & $23.49 \%$ \\
\hline & $35-39.9$ & 44 & $38.26 \%$ \\
\hline & $40-44.9$ & 11 & $9.56 \%$ \\
\hline & $45-49.9$ & 5 & $4.35 \%$ \\
\hline & $50-54.9$ & 2 & $1.74 \%$ \\
\hline & $55-59.9$ & 2 & $1.74 \%$ \\
\hline \multirow{3}{*}{$\begin{array}{c}\text { Level of Highest } \\
\text { Education Attained }\end{array}$} & High School/Diploma & 22 & $19.13 \%$ \\
\hline & First Degree & 57 & $49.57 \%$ \\
\hline & Post Graduate & 36 & $31.30 \%$ \\
\hline \multirow{3}{*}{$\begin{array}{l}\text { Nature of Internet } \\
\text { Protocol use }\end{array}$} & Mainly Professionally & 85 & $73.91 \%$ \\
\hline & Mainly Private & 30 & $26.09 \%$ \\
\hline & Both & & \\
\hline \multirow{8}{*}{$\begin{array}{l}\text { Practical experience } \\
\text { regarding Internet } \\
\text { Protocol networking } \\
\text { administration }\end{array}$} & $0-1.9$ & 15 & $13.04 \%$ \\
\hline & $2-3.9$ & 18 & $15.65 \%$ \\
\hline & $4-5.9$ & 22 & $19.13 \%$ \\
\hline & $6-7.9$ & 13 & $11.30 \%$ \\
\hline & $8-9.9$ & 7 & $6.09 \%$ \\
\hline & $10-11.9$ & 21 & $18.26 \%$ \\
\hline & $12-13.9$ & 5 & $4.35 \%$ \\
\hline & $14-15.9$ & 4 & $3.48 \%$ \\
\hline \multirow{5}{*}{ Nature of Job Role } & Software Development & 16 & $13.91 \%$ \\
\hline & Network Engineer \& Analyst & 42 & $36.52 \%$ \\
\hline & Education [Teachers \& Students] & 32 & $27.83 \%$ \\
\hline & Government IT Manager & 7 & $6.09 \%$ \\
\hline & Others & 8 & $6.96 \%$ \\
\hline \multirow{4}{*}{$\begin{array}{l}\text { Place of residence } \\
\text { in the country [closest to] }\end{array}$} & Yaoundé & 46 & $40.00 \%$, \\
\hline & Bamenda & 24 & $20.87 \%$ \\
\hline & Douala & 21 & $18.26 \%$ \\
\hline & Garoua & 14 & $12.17 \%$ \\
\hline
\end{tabular}


the institutional current status to support the deployment of IPV6?" Available options for IPv6 situation at their institution were: 1) have been deployed; 2) deployment in progress; 3) deployment is being planned; 4) Ipv6 have been discussed; 5) no current plan or discussion. Figure 3 shows the responses of the study sample.

The analysis of the options as shown in Figure 3 shows that $48 \%$ of the respondents viewed that IPv6 has not been planned or discussed followed by $38 \%$ of the respondents thought that there has been a discussion among the engineers in their organization. This finding shows that IPv6 is not largely considered for implementation by the organizations. Findings above reveals that awareness in the institutions in Cameroon about IPv6 is generally low with exception of the self-learning efforts among their staff members to educate themselves. With only $1 \%$ reporting IPv6 deployment, it is remarkable demonstration of shortages of influencers and champions in organizations.

\subsubsection{Importance of Each Identified Factor Standing in the Way of Bigger Internet with Virtually Unlimited IP Address}

The participants presented a good understanding of the concept of the IPv6 technology. Thus, to address another major aim of this study, the 115 respondents were asked, on behalf of their organization, to assess the importance of each concerns identified by the six experts from the phase 1 study to their organizations' current technological landscape. That is how significant does each of what stands in the way of bigger Internet with virtually unlimited IP Address [IPv6] in Cameroon from their perceptive are.

For instance, a completely unimportant position on "Not seeing IPV6 technology as an open system" mean exactly that whereas high percentage scores in very important position in an area meant high concern. Table 2 illustrates the accumulated calculations per each variable.

Industry stakeholders, specialists and scientist generally agree to the fact that the adoption of IPv6 is not a matter of "how", "why" or "who" but only of "when". Some organizations did not see IPv6 as a priority and did not see a reason to adopt IPv6 The results show that more than half of the surveyed population $(62 \%)$ agreed to the position of Very Important that people in Cameroon viewed IPv6 technology as something for the distant future, while (59\%) selected

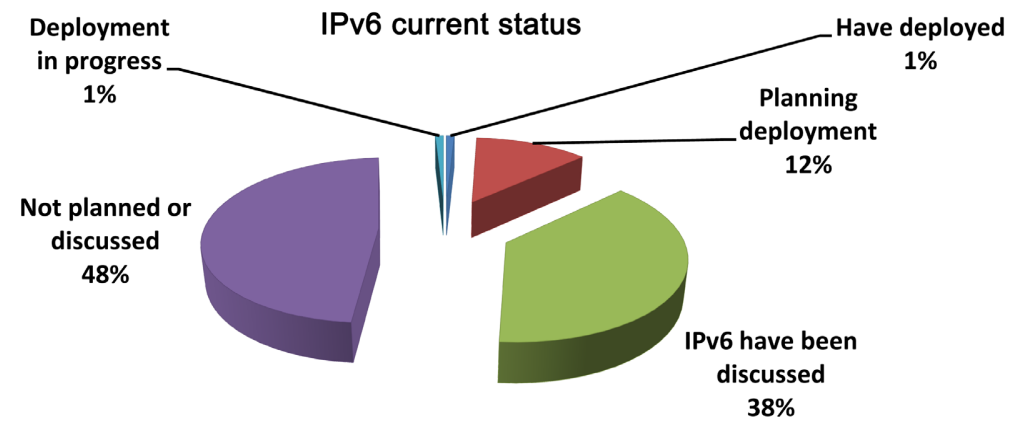

Figure 3. IPv6 current situation. Source: Authors. 
Table 2. Importance of what stands in the way of bigger internet with virtually unlimited IP address in Cameroon, according to all respondents [\%].

\begin{tabular}{|c|c|c|c|c|c|}
\hline \multirow{2}{*}{$\begin{array}{l}\text { Issues that are } \\
\text { relevant to a } \\
\text { decision to change }\end{array}$} & \multicolumn{5}{|c|}{ Importance } \\
\hline & $\begin{array}{c}\text { Completely } \\
\text { unimportant } \\
\%\end{array}$ & $\begin{array}{c}\text { Not } \\
\text { important } \\
\%\end{array}$ & $\begin{array}{l}\text { Difficult } \\
\text { to say\% }\end{array}$ & $\begin{array}{c}\text { Important } \\
\%\end{array}$ & $\begin{array}{c}\text { Very } \\
\text { Important } \\
\%\end{array}$ \\
\hline $\begin{array}{l}\text { Not seeing IPv6 } \\
\text { technology as an open } \\
\text { system }\end{array}$ & 25.22 & 33.04 & 23.48 & 13.04 & 5.22 \\
\hline $\begin{array}{l}\text { understanding IPv6 } \\
\text { Innovation Generation } \\
\text { opportunity }\end{array}$ & 3.48 & 33.04 & 6.96 & 39.13 & 17.39 \\
\hline $\begin{array}{l}\text { High IPv6 infrastructure } \\
\text { cost including } \\
\text { infrastructure upgrade } \\
\text { and deployment operation }\end{array}$ & 6.96 & 22.61 & 15.65 & 29.57 & 25.22 \\
\hline $\begin{array}{l}\text { The need for government } \\
\text { and organizations to invest } \\
\text { in adequate staff training }\end{array}$ & 5.22 & 6.09 & 10.43 & 19.13 & 59.13 \\
\hline $\begin{array}{l}\text { Lack of government policy } \\
\text { drivers including financial } \\
\text { incentives encouraging } \\
\text { transition to IPv6 }\end{array}$ & 0.87 & 6.96 & 33.91 & 47.83 & 10.43 \\
\hline $\begin{array}{l}\text { IPv6 technology is } \\
\text { something for the } \\
\text { distant future }\end{array}$ & 6.96 & 13.04 & 10.43 & 6.96 & 62.61 \\
\hline
\end{tabular}

Very Important position for the factor that emphasize on The need for government and organizations to invest in adequate staff training.

This findings is not remarkable so different from the findings of Dell et al. [21] who said although almost $75 \%$ believed that IPv6 was important for their organization's future, only $39 \%$ believe that IPv6 should be implemented at the current time. IPv6 technology is thus a highly important and pressing issue, but it is not time to adopt it majority of our respondents thinks. Lack of government policy drivers including financial incentives encouraging transition to IPV6 is another factor that attracted [47.83\%-Important] and [10.43\%-very important] positions. This factor is one of the major recommendations by Nwabueze et al. [22] in a study that design a model for predicting migration from IPV4 to IPV6 in Nigeria by 2027. Government regulations many authors has argued reduce the level of risk and uncertainty about the future of a new standard.

Studying general drivers and barriers in adoption of IPv6, different researchers have argued that organizations that intend to adopt IPv6 need to have adequate organizational resources. The economics of the transition to IPv6 can be diverse. Various initial costs required to deploy, cost of compatibility, negligible cost of acquiring IPv6 numbers and general cost of equipment and its configura- 
tion has been identified as key factor that may influence the organizational readiness to migrate to IPv6 [23] [24]. In this study, high IPv6 deployment cost including infrastructure upgrade and deployment operation proves to be a concern as indicated by $54.78 \%$ of respondents who rated this as either an important or a very important drivers and barriers. According to Dell et al. [21], in a similar study in the Indonesia, almost half (47\%) of the respondents believed that IPv6 would involve high costs, while only $25 \%$ believed it would not. A total of $33.04 \%$ of the respondents said understanding $I P_{V} 6$ as an Innovation Generation opportunity is not important. This is remarkable when considered in relation to the unequivocal statement made by APNIC some years ago: "IPv6 is the only means available for the sustained ongoing growth of the Internet, and [we urge] all Members of the Internet industry to move quickly towards its deployment." Shortage of labor with relevant IPv6 skills in Cameroon (evidence by $59.13 \%$ of the participants stating that it is very important for government and organizations to invest in adequate staff training) may exacerbate any seeming IPv6 innovation opportunities.

\section{Conclusion \& Future Research}

The purpose of this paper was to investigate the factors standing in the way of bigger Internet with virtually unlimited IP Address [IPv6] in Cameroon and considered as significant. Majority of the institutions in Cameroon still see IPv6 technology as an issue that will only affect them in the distant future. There is a strong awareness of the need to push policies to promote IPv6 deployment at national government level. There is a strong call and need for government and organizations to invest in adequate staff training. Review of the literature remarkably demonstrates that government measures to encourage IPv6 adoption can be successful, but in Cameroon there has been little government involvement to the best of our knowledge. Hovav et al. [25] recommend a number of means to speed the diffusion of IPv6 through the Internet: sponsorship; policy setting; encouraging backwards-compatible products; and encouraging transitional and related technologies. Some of these approaches have been implemented in various countries. One of the experts [from a government agency] in our focus group study speaking anonymously said that the Cameroon Government currently has no proposal to mandate IPv6 for government agencies. Government action or inaction at least in Africa influences adoption and adaption of innovative technologies. Country like China [26] is pushing for the adoption of IPv6 that could the internet bigger and faster. Given the apparent success of government intervention in other countries, it is proposed here that action within government agencies to seed wider industry adoption and the possibility of regulatory intervention may both be reasonable in Cameroon and should at least be considered. In general, the results of this study revealed that IPv6 was not sufficiently attended to by various organizations in Cameroon. Despite the aforementioned results, alternative contexts of this study could be considered for future work, such as 
investigating the impact IPv6 will have on the contribution of ICT to economic growth and ways to strategize and implement for IPv6.

\section{Conflicts of Interest}

The authors declare no conflicts of interest regarding the publication of this paper.

\section{References}

[1] Cenfetelli, R.T. and Schwarz, A. (2011) Identifying and Testing the Inhibitors of Technology Usage Intentions. Information Systems Research, 22, 808-823. https://doi.org/10.1287/isre.1100.0295

[2] Bhattacherjee, A. and Hikmet, N. (2007) Physicians' Resistance toward Healthcare Information Technology: A Theoretical Model and Empirical Test. European Journal of Information Systems, 16, 725-737. https://doi.org/10.1057/palgrave.ejis.3000717

[3] Hirschheim, R. and Newman, M. (1988) Information Systems and User Resistance: Theory and Practice. The Computer Journal, 31, 398-408. https://doi.org/10.1093/comjnl/31.5.398

[4] Kleijnen, M., Lee, N. and Wetzels, M. (2009) An Exploration of Consumer Resistance to Innovation and Its Antecedents. Journal of Economic Psychology, 30, 344357. https://doi.org/10.1016/j.joep.2009.02.004

[5] Venkatesh, V., Thong, J.Y.L. and Xu, X. (2012) Consumer Acceptance and Use of Information Technology: Extending the Unified Theory of Acceptance and Use of Technology. MIS Quarterly, 36, 157-178. https://ssrn.com/abstract=2002388 https://doi.org/10.2307/41410412

[6] Bohlin, E. and Lindmark, S. (2002) Incentives to Innovate with Next Generation Networks. Communications \& Strategies, 48, 97-117.

[7] Dell, P. (2010) Two Economic Perspectives on the IPv6 Transition. Info, 12, 3-14. https://doi.org/10.1108/14636691011057046

[8] Meena, R.C. and Bundele, M. (2015) A Review on Implementation Issues in IPv6 Network Technology. International Journal of Engineering Research and General Science, 3, 800-809. https://ssrn.com/abstract $=3569454$

[9] Deering, S.E. and Hinden, R.M. (1998) RFC 2460: Internet Protocol, Version 6 (IPv6). IETF. https://tools.ietf.org/html/rfc2460 https://doi.org/10.17487/rfc2460

[10] Google (2021) IPv6 Statistics. https://www.google.com/intl/en/ipv6/statistics.html

[11] Jackson, S., Hitchins, D. and Eisner, H. (2010) What Is the Systems Approach? April 2010. Insight INCOSE (1). https://doi.org/10.1002/inst.201013141a

[12] Creswell, J.W. (2008) Qualitative Inquiry and Research Design: Choosing among Five Approaches. 3rd Edition, SAGE Publications, Los Angeles.

[13] Puchta, C. and Potter, J. (2004) Focus Group Practice. SAG, London. https://doi.org/10.4135/9781849209168

[14] Ajzen, I. (1991) The Theory of Planned Behavior. Organizational Behavior and Human Decision Processes, 50, 179-211. https://doi.org/10.1016/0749-5978(91)90020-T

[15] Rogers, E.M. (1983) Diffusion of Innovations. University of Illinois at UrbanaChampaign's Academy for Entrepreneurial Leadership Historical Research Ref- 
erence in Entrepreneurship.

[16] Corbin, J. and Strauss, A. (2014) Basics of Qualitative Research: Techniques and Procedures for Developing Grounded Theory. SAGE Publications, Inc., London, $456 \mathrm{p}$.

[17] Nguyen, M., Anh, N., Rantapuska, T., Utriainen, J. and Matilainen, M. (2012) Transition from IPv4 to IPv6: The Method for Large Enterprise Networks. The First International Conference on Communications, Computation, Networks and Technologies, Venice, 21-26 October 2012, 5-14.

[18] Dobrijevic, O., Svedek, V. and Matijasevic, M. (2012) IPv6 Deployment and Transition Plans in Croatia: Evaluation Results and Analysis. 20th International Conference on Software, Telecommunications and Computer Networks (SoftCOM), Split, 11-13 September 2012, 1-7.

[19] Malobe, L.C.M. and Amaechi, A.O. (2021) Integrating Voice over IP Solution in IPv6 and IPv4 Networks to Increase Employee Productivity: A Case Study of Cameroon Telecommunications (Camtel), North-West. Journal of International Technology and Information Management, 30, Article 3. https://scholarworks.lib.csusb.edu/jitim/vol30/iss1/3

[20] Rajgor, M., Paresh, C., Dhruv, P., Chirag, P. and Dhrmesh, B. (2016) RII \& IMPI: Effective Techniques for Finding Delay in Construction Project. International Research Journal of Engineering and Technology, 3, 1173-1177.

[21] Dell, P., Kwong, C., Syamsuar, D., François, S. and Choy, K. (2009) A Comparison of Attitudes to IPv6 in Three Countries. Jurnal Sistem Informasi (JSI), 1, 258-271.

[22] Nwabueze, E.E., Nwosu, C.E. and Osuagwu, O.E. (2018) A Model for Predicting Migration from IPV4 to IPV6 by 2027 in Nigeria. Open Journal of Modelling and Simulation, 6, 45-57. https://doi.org/10.4236/ojmsi.2018.63004

[23] Main, A., Zakaria, N.A. and Yusof, R. (215) Organisation Readiness Factors towards IPv6 Migration: Expert Review. Procedia-Social and Behavioral Sciences, 195, 1882 1889. https://doi.org/10.1016/j.sbspro.2015.06.427

[24] Brenden, K. (2019) Economic Factors Affecting IPv6 Deployment. TeamARIN Published May 2, 2019. https://doi.org/10.2139/ssrn.3410895

[25] Hovav, A., Patnayakuni, R. and Schuff, D. (2004) A Model of Internet Standards Adoption: The Case of IPv6. Information Systems Journal, 14, 265-294. https://doi.org/10.1111/j.1365-2575.2004.00170.x

[26] Xie, J. (2020, August 12) China Embraces Bigger Internet with Virtually Unlimited IP Addresses. Voice of America. https://www.voanews.com/east-asia-pacific/voa-news-china/china-embraces-bigger -internet-virtually-unlimited-ip-addresses 